\title{
Article
}

\section{Efficiency through a Lean Healthcare Implementation in a Public Hospital}

\author{
Luisa Rosas-Hernandez ${ }^{1}$, Diego Tlapa ${ }^{1^{*}}$, Yolanda Baez-Lopez ${ }^{1^{*}}$, Jorge Limon-Romero ${ }^{1^{*}}$, Armando \\ Perez-Sanchez ${ }^{2}$
}

1 Facultad de Ingeniería, Arquitectura y Diseño, Universidad Autónoma de Baja California. Carretera Transpeninsular Ensenada-Tijuana 3917, CP 22860, Ensenada, México.

2 Facultad de Ciencias de la Ingeniería y Tecnología, Universidad Autónoma de Baja California, Blvd, Universitario \#1000, Unidad Valle de las Palmas, Baja California CP. 21500, Tijuana, Mexico.

* Correspondence: diegotlapa@uabc.edu.mx (D.T.); yolanda@uabc.edu.mx (Y.B.); jorge.limon@uabc.edu.mx (J.L.); Tel.: +52-6461750744 (D.T.)

\begin{abstract}
Hospitals face challenges to improve efficiency in order to meet an increasing demand for high quality of care and low costs. Industry-based methods such as lean healthcare (LH) are implemented to improve healthcare systems. This study presents a LH implementation following the DMAIC approach (Define-Measure-Analysis-Improve-Control) in a Mexican public hospital, and contributes to the literature by analyzing the relation of waste reduction and sustainability. We focused on improving the medical supply chain from a temporary warehouse (TW) to the operating room (OR). Therefore, we analyzed the value stream including main surgical procedures and their related medical supplies, and identified different causes of inefficiency, which were evaluated and controlled. As a result, five types of waste were reduced, through different tools including, value stream map, Kanban, 5's, among others. Over-processing requests were reduced $15.3 \%$; similarly, defective identification numbers were reduced up to $46.5 \%$, redundant processing was improved by $94.8 \%$, unnecessary inventories were reduced near to $2.8 \%$ of the TW inventory, and transportation waste was reduced up to $16.7 \%$. As a consequence, the lead-time for the main supplies was reduced 33 days. Results indicate that LH and DMAIC are effective to reduce waste and highly conducive to improve healthcare process sustainability.
\end{abstract}

Keywords: Lean Healthcare, DMAIC, waste reduction, efficiency, sustainability.

\section{Introduction}

Healthcare organizations face continuous pressure to increase efficiency and reduce waste [1]. Efficiency has become a main goal because it impacts on safety, quality, and costs. To increase efficiency, hospitals around the world are implementing LH in their processes with a focus on eliminating waste while increasing the value of a business process [2]. Here, values are "activities that enhance the quality of healthcare and promote patient well-being so as to achieve better outcomes" [3]. Conversely, waste are aspects of the service that do not add value to customers [2] and are commonly grouped into seven types that LH aims to reduce: transportation, inventory, motion, waiting, overproduction, over-processing and defects (Beck, Okerblom, Kumar, Bandyopadhyay, \& Scalzi, 2016; Westwood, James-Moore, \& Cooke, 2007); though literature add underutilized skills as an eighth waste [6]-[8].

The term "lean" originates from the Toyota Production System (TPS), a popular system due to the efficiency shown in Japanese manufacturing companies [9]. Lean as a system reached the 
medical domain in the early 2000s commonly known as lean healthcare [10], [11]. Increasing the efficiency of hospital-based clinical care by applying TPS (lean) is identified as a potent strategy to lower costs and improve outcomes [12]. Thus, different successful case studies of LH are reported including: establishing streams for patient flows in an emergency department (ED) [13], improving throughput in ED [14] and cardiac catheterization [15], improving patient flow in Gynecologic Oncology clinics [16], reducing the wasted time associated with drug dispensing [17], reducing ED length of stay [18], minimizing blood test and waiting time [19], reduction of patient transportation and waiting times [20],[21], among others.

Another strategy used to increase efficiency is Six Sigma (SS) which was created to improve product quality by identifying errors and mistakes in manufacturing and business processes [22]. In order to solve problems and reduce variation, SS follows a well-established method known as DMAIC. Studies applying SS in healthcare include the reduction of variability in scheduling pre-anesthesia consultations [23], reduction of appointment lead-time in obstetrics outpatient department [24] among others. The synergy of both LH and SS methodologies, that is LSS, seems to be one of the most innovative and effective approaches in "Operational Excellence" [25], and are effective quality improvement methods widely adopted by manufacturing industries that are currently also implemented in many health care settings [26]. In the field of health care, LSS has been used to address numerous health care problems [27], some of them include areas as: Trauma center [28], Cardiology[29], Surgery [30], operating room [31], Intensive care unit [32], rehabilitation ward [23], and Otolaryngology care [33].

Accordingly, general lean and six sigma principles are interpreted and adapted for each organization's unique local context. Despite LSS is excellent for driving process change, it has limitations in the complex social environment of hospitals [30].

\subsection{Lean Healthcare and the economic, environmental and social perspective.}

Healthcare professionals and managers in many countries are experimenting with lean tools and techniques to improve efficiency, clinical outcomes, satisfaction and safety for both staff and patients and ultimately to enhance financial performance and sustainability [25]. In this regard, sustainability researchers hold multiple perspectives that range from sustaining results over time [25], to concerning with the capability of meeting those needs in the present and future (efficacy, effectiveness and ethics) [34]. In this research we used the latter perspective.

For sustainable development to be achieved in organizations, it is crucial to harmonize three core elements: economic growth, social inclusion and environmental protection [35]. In the economical component, while reducing waste, LH helps to reduce costs. Worldwide, there have been many LH implementations with an impact on operational indicators, these include the increase in service capacity [[36]; [23]]; productivity increase [[37]; [38]]; reduction in cost per case/service [[30]; [39]]; reduction of inventory/space [[38]; [14]; [40]]; reduction in transit/transportation time [[41]; [14]]; and reduction in process cycle time among others [[29]; [17]; [42]; [13]].

In the environmental component, lean produces an operational and cultural environment that is highly conducive to waste minimization and pollution prevention. In fact, while reducing waste, lean has a positive contribution in the improvement of the environmental performance [43]. Besides, health units are taking steps to improve energy consumption, renew the way they work, and design more environmentally friendly facilities [44]. In addition, some tangible results of the implementation of lean approach in hospitals include the reduction in energy consumption [45].

In the social component, $\mathrm{LH}$ is positively related to social outcomes such as organizational effectiveness, in terms of service quality, customer/patient satisfaction among other sociocultural aspects [46]. To increase patient satisfaction, LH has demonstrated its potential through the reduction of patient transportation and waiting times [20], [21].

Despite the inherent relation between LH and sustainability, Hallam and Contreras (2018) found that only $13.5 \%$ of LH literature included sustainability as a part of those researches [47]. In a global context lean initiatives first appeared in UK health service and then in the USA [48], and, indeed, LH have been predominantly implemented in developed countries [49], [50]. In fact, 
literature review showed scarcity in the studies from developing countries [51]. Moreover, there is little evidence of LH implementation at public hospitals; accordingly, there is a need to analyze how LH can be implemented into a particular situation as a basis for explaining the success (or otherwise) of such improvement strategy. Therefore, in this study a LH implementation is conducted to address deficiencies within the medical supply chain in a public hospital in Mexico.

\section{Materials and Methods}

A lean healthcare implementation following the DMAIC approach, i.e. the five-phase improvement cycle, was conducted from February 2017 to December 2018 on a Public Hospital in Mexico. We decide to conduct an explanatory single case study since it is particularly useful when a subject requires comprehensive investigation from multiple perspectives [52]. The hospital attended to 9,162 patients during 2018, it has 127 permanent care beds and 104 temporary care beds, staffed with 444 nurses and 120 doctors that work in the 42 different services that the hospital offers. The hospital presents a wide variety of opportunities areas regarding efficiency in different processes as well as in the use of infrastructure and supplies. This project carried out an analysis of inefficiencies in the medical supply process, which represent high volume and costs for the hospital. In conjunction with hospital authorities, we determined to follow the DMAIC approach because it offers great usefulness for improvement of pre-existing processes and has been implemented in similar cases [22], [26].

Following the proposed methodology, in the define phase we reviewed historical data, conducted staff meetings and interviews with heads of departments. In addition, we evaluated the value stream of main processes, conducted exploratory walks through the hospital, which allowed us to generate an initial diagnostic. In this regard, the needs of the hospital authorities were identified, as well as the ones of the internal customers (42 different hospital services). We defined an opportunity area in the internal medical supply chain, which begins in a general warehouse of the medical unit (WU), providing supplies to a temporary warehouse (TW) near the facilities where they are used. This TW provides supplies every day to the 42 services of the hospital. Particularly, we focused on the Operating Room (OR) supply chain, being this service the most critical area according to hospital authorities and because it represents the biggest volume of supplies.

In the measure stage, in order to identify key variables, a brainstorming meeting with staff and a survey was conducted; in addition, a cause-effect diagram was created to identify possible causes of inefficiency (Figure 1). Subsequently, the routes to the different hospital areas that receive supplies from the TW were described and quantified in a spaghetti diagram, then the areas representing greater movement and transport were identified (Figure 2). Furthermore, volume, type of supplies and the main services where the supplies are delivered were determined using the Pareto analysis (Figure 3). In this sense, the demand for supplies from all services for the years 2017 and 2018 were gathered and examined to understand the pattern of variation. In addition, we elaborated a SIPOC diagram with representative processes and supplies, which were grouped by product families.

In the analyze stage, the main surgeries conducted in the OR were analyzed to determine frequency, volume and type of supplies required in the OR that would satisfy the requirements of these surgical procedures. Then, we developed a surgical demand analysis and forecast using historical data of the years 2016, 2017 and 2018; for this, different time series methods were evaluated including moving average, single and double exponential smoothing, and Holt-Winters as proposed by [53]. Afterward, in order to attain a better understanding of the supply process, a value stream map was generated for the most used family of supplies of OR (Figure S1). Therefore, we identified activities that generate value and those who don't, in an effort to reduce waste.

In the improvement stage, with the commitment and participation of the TW staff, we implemented a 5'S program to reorganize the workplace, enhance the cleaning process and to improve access and space in the TW, which allowed better control of supplies. Moreover, by analyzing the supply demand in the OR and with the most representative families of supplies, an initial inventory management program was developed as well as the oversight of supply deliveries 
from the TW. The need to generate supply batches and calculate the average demand was identified, from which a future VSM was developed in order to improve the process (Figure S2). In addition, a Kanban system was developed for supply and stock management (Table S1).

Finally, in the control stage, different procedures and instructions were developed and control activities were implemented, including $5^{\prime} \mathrm{S}$ audits, which consists in formats for the verification of the execution of the improvement activities, reviewing if they were implemented, if any changes were proposed and if they were approved by senior management, in such a way that a value can be assigned to each activity so they can be monitored, and the improvement can be guaranteed.

\section{Results}

The LH intervention in the medical supply chain was conducted. Initially, after a brainstorming session we identified several possible causes regarding deficiencies in the medical supply chain from TW, which were organized using cause-effect diagram as shown in Figure 1.

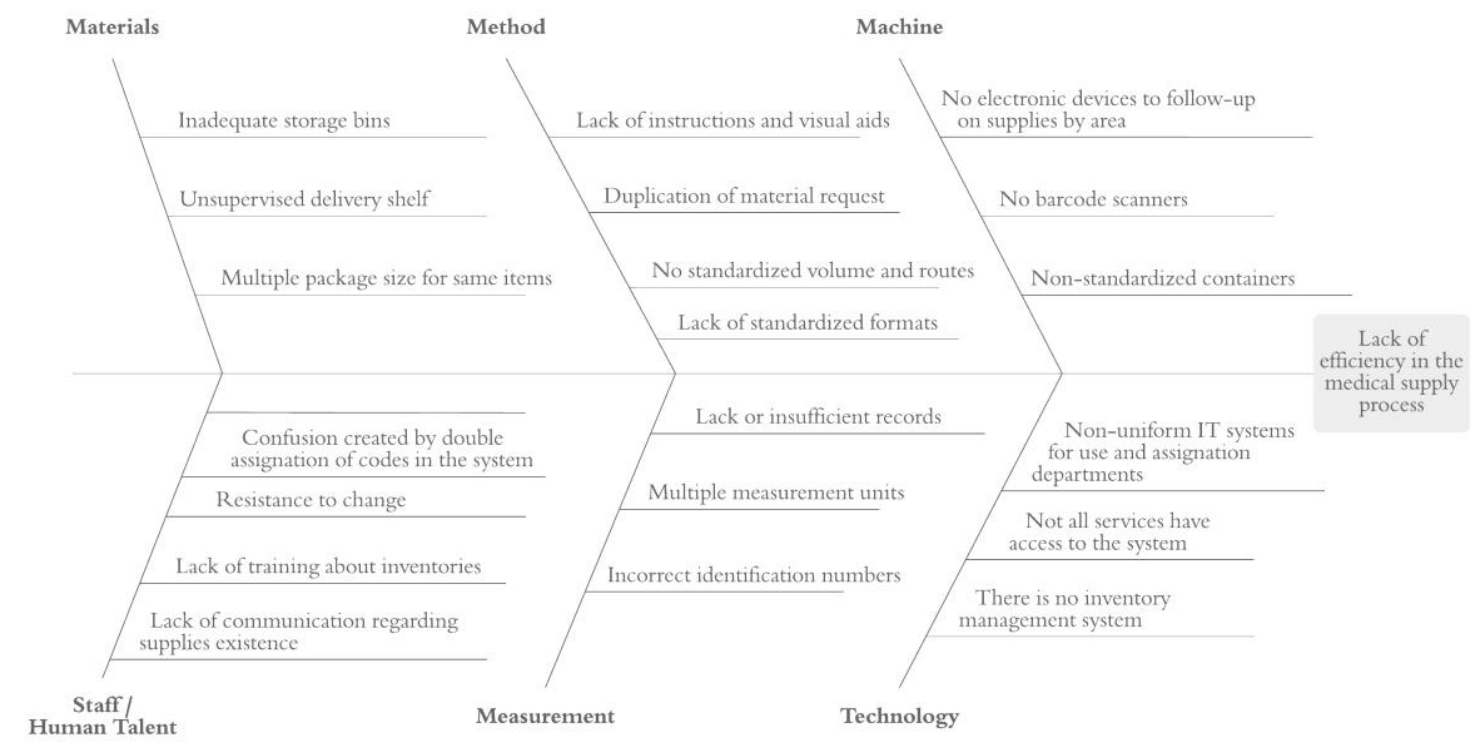

Figure 1. Cause-effect diagram of the lack of efficiency in the medical supply process

Regarding the supply variation, TW provides medical material to 42 different areas, some of them requesting more material and in a higher frequency per day. From the supply analysis we identified that the OR as an independent service is the one making the highest amount of requisitions from TW, as shown in the Pareto graph (Figure 3). Therefore, main surgical procedures and their related medical supplies were analyzed for the years 2016, 2017 and 2018. From the 464 different surgical procedures registered, it was found that the most representative were Caesarean sections with 3.7 daily procedures on average, followed by tubal ligation and appendectomy. The demand analysis for C-section obtained better results with Holt-Winter model $(\alpha=0.5, \beta=0.05$, $\mathrm{MAPE}=0.119, \mathrm{MAD}=27.8$ ), which allowed us to develop a Kanban system to provide the correct amount of supplies on a daily basis to OR, from which an extract is shown in Table S1. 


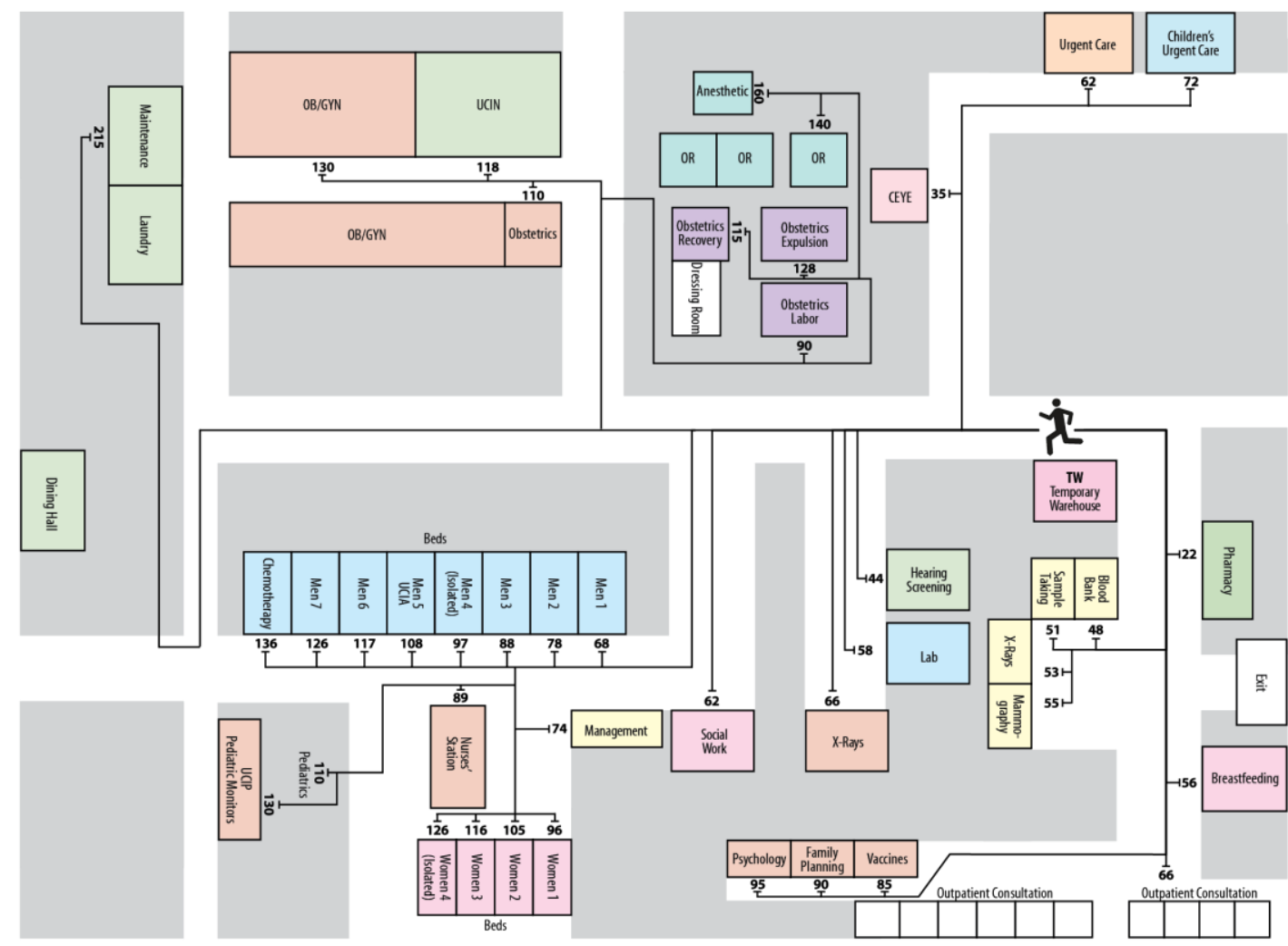

Figure 2. Spaghetti Diagram indicating distances from TW to each area (numbers represent the steps)

In relation to transport and staff mobility, from the 42 different areas that the TW supplies, the nearest one is approximately at 22 steps while the farest is located 215 steps away, as can be seen in the Spaghetti diagram in Figure 2. Despite OR area is located at 90 steps away from TW, with the Kanban system controlling the amount and frequency of main supplies to the OR, along with the development of a procedure and instructions to correctly request and process a requisition, re-organization of internal supply routes, as well as proper training, allowed us to reduce transportation up to $16.7 \%$.

In connection with the value stream map for the main supplies from TW to OR, we identified that up to $60 \%$ of requisitions made to the TW were not correctly provided in quantities and type of supplies, generating multiple request orders. This type of over-processing waste was reduced $15.3 \%$. Furthermore, the future value stream map indicated a 33 days reduction in the lead-time from 45.3 days to 11.9 days for 3 families of needles, which represented the highest volume of supplies. Additionally, several inconsistencies were found respecting identification, location, and inventory volume. In this sense, with the commitment and participation of the staff from the different shifts of the TW, the implementation of the 5'S program allowed to organize the workspace and to have better control of supplies Figure S3 and Figure S4. 


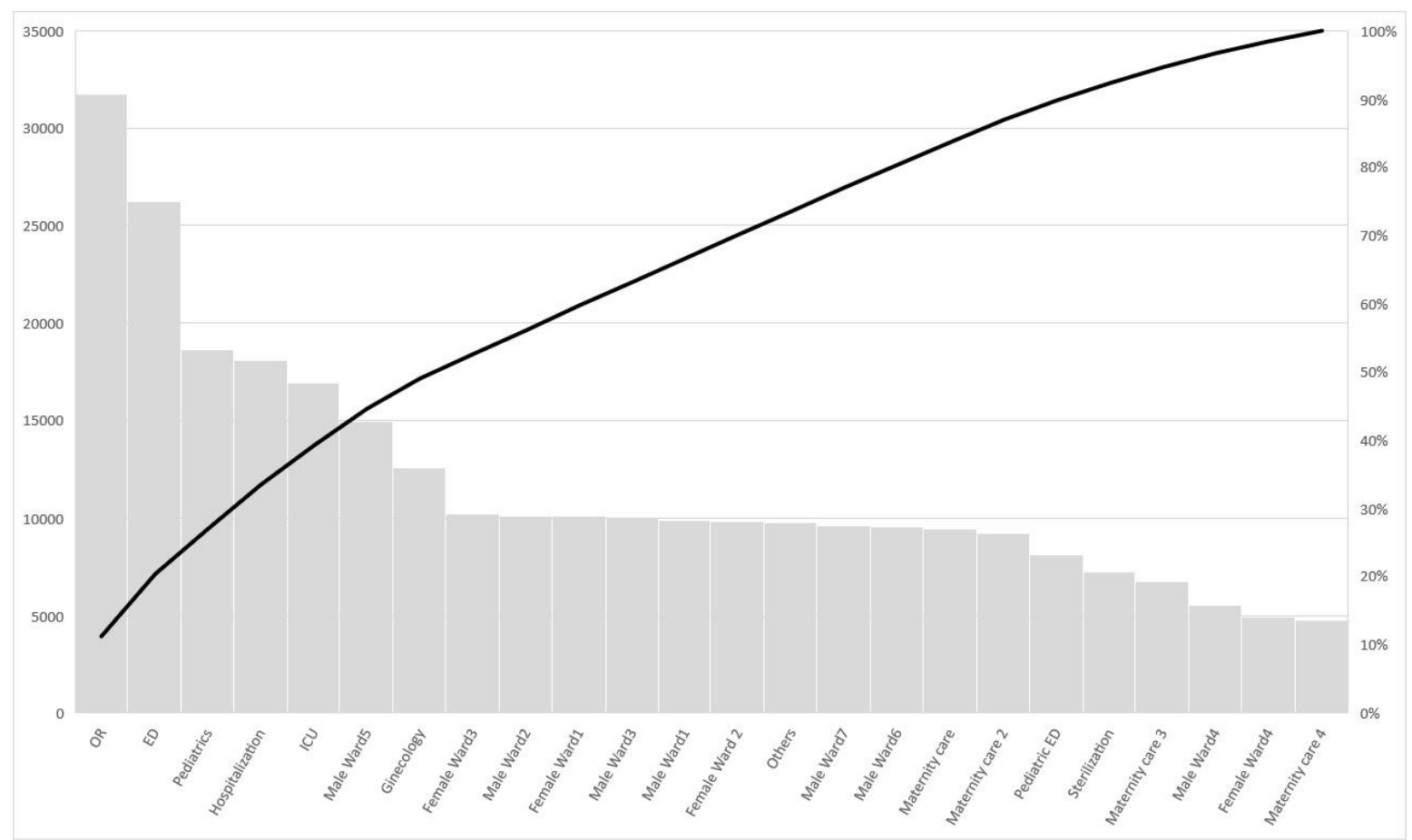

Figure 3. Pareto graph with frequencies of supplies requests by areas during 2017 and 2018.

Moreover, the analysis of codes and identification numbers of all the supplies in the TW system showed 8,256 different items, however, after removal of duplicates or inexistent items, only 4,413 were identified as real items, that is a reduction of $46.5 \%$ of defective identification numbers, which in turn might traduce in other type of waste. One of the largest reductions of waste was obtained through the elimination of redundant processing and reduction of reentry material orders by the different areas, which was improved by $94.8 \%$, from 7,523 to only 388 . In addition, we were able to identify and eliminate unnecessary inventories among services, which represented near to $2.8 \%$ of the TW inventory.

\section{Discussion}

Based on the results, five different types of waste were reduced in a public hospital through a LH implementation following the DMAIC approach. Even though waste was not eliminated, an important step was done considering resources limitations from a public hospital. Through the reduction of inventory and transportation from the TW to the OR, allowed to have better control of the warehouse, medical supplies and the time of the staff. Furthermore, reducing processing, over-processing, and defective identification numbers, the supply process performance was improved. These findings are similar to [54] regarding LH has an impact on the supply performance through the medical supply chain. Other benefits of LH include the improvement of the quality related to patient care, safety, elimination of delays and reduction length of stay [4]. Moreover, This research supports the findings cited earlier of McCulloch et al. (2010) who found extensive evidence of the benefits of lean in improving efficiency in medical settings [55].

Different efforts to improve efficiency in OR have been made including: reduction of length of stay [30]; reduction of door movements number [56]; reduction of unnecessary instruments delivered to the OR [57]; decrease of turn-over time (TOT) [58] among others. This study complements the literature and provides a different perspective from a public hospital located in a developing country, what might give insights to researchers and practitioners. In addition, we gained knowledge of the process and got better understanding of the compatibility and impact on sustainability of LH and SS initiatives, which might be extended to more healthcare processes. 
Despite this research was conducted mainly in the supply process to the OR, LH and SS present a wide dispersion in other areas ranging from surgical waiting lists, emergencies, laboratory, time of occupation of operating rooms, recruitment of personnel, errors in medication, and management maintenance work orders [56], [59], [60]; Thus, suggesting the flexibility of LH and SS to be implemented in different areas of a hospital.

\subsection{Waste reduction and sustainability}

Waste definition of lean includes both tangible and intangible factors, such as inefficient machinery and non-value-added movement, respectively, whereas sustainability refers to more tangible issues, such as resource consumption, emission levels, and physical material dumped into landfill [61]. Moreover, lean and six sigma aims to reduce waste and variation, offering a better culture to deploy sustainability. On the other hand, sustainability aims to minimize negative impacts of processes and activities on the environment, society, and assets [61]; thereby, there is a clear the similarity among lean, six sigma and sustainability: waste reduction [61]-[63].

These efforts seems to be a war on waste, however, this is just justified by the need to reduce costs that are not essential for the care of patients [64]. Despite the major threat to health service sustainability is most often identified as financial, healthcare, as with all human activity, takes place within a social and environmental context, not just an economic one [65]. Therefore, the war on waste has now more justification, the need for greener healthcare [64], and social impact as well. From a broad perspective of lean, most of the literature concentrates on either cost minimization or profit maximization, and on reducing environmental emissions. Only a few studies examine the effects of lean on sustainability from the economic standpoint [34].

In addition, LH is positively related to social outcomes such as organizational effectiveness, in terms of service quality, customer/patient satisfaction among other sociocultural aspects [46]. Accordingly, several benefits are reported by practitioners related to those perceived by the patients i.e. reduction in the length of stay [[66]; [67]; [30]]; waiting time reduction [[13]; [68]; [69]]; increase patient safety [[56]; [57]]; reduction in time response/lead time [[38]; [68]; and ultimately, all these types of benefits impact in increase of the patient satisfaction [66]; [38]. However, doctors, nurses, employees and staff also perceived benefits from LH implementation, these include the increase employee satisfaction and motivation [68]; [70]; and empowerment [40]; [4].

In the environmental side, lean produces an organizational culture that is highly conducive to waste minimization, pollution prevention, environmental management systems, and sustainability [71]. In fact, while reducing waste, lean has a positive contribution in the improvement of the environmental performance [43]. Thus, health units are taking steps to improve energy consumption [45] or to reduce waste, renew the way they work, and design more environmentally friendly facilities [44].

An important aspect while implementing LH in public hospitals is in relation with the type of management and the bureaucracy, which is common to public sector. Therefore, we agree with Radnor and Osborne (2013) regarding the challenges that public services face implementing lean, e.g. the impact of public sector culture and structures, and particularly the competing professional and managerial role, as well as the lack of understanding of the centrality of the customer (or service user) and of service process [48]. Other opportunities include the extension of the 5'S to 6'S to obtain an additional layer to ensure occupational safety and health levels [72]. In this regard, lean practices and projects may facilitate the focus on sustainability [73], including approaches to integrate lean with different management system such quality, environment, occupational health-safety, and social responsibility [74].

In a global context, the United Nations (UN) stated the 2030 Agenda for Sustainable Development and the associated Sustainable Development Goals -SDGs- [75]. Worldwide there have been several efforts to contribute to sustainability. The National Health Service (NHS) England developed its Sustainable Development Management Plan 2018-2020 which is aligned to the SDGs [76]. In the US, the Environmental Protection Agency created a foundational framework for environmental sustainability using lean tools to improve both business performance and 
environmental performance by identifying and eliminating environmental wastes at organizations [77]. However, there are still opportunity areas to cover, mainly in developing countries. In addition, more research focusing on LH, SS and sustainability is needed, mainly because sustainability remain underestimated themes in LH literature [25].

Finally, this study has several limitations. First, it was conducted in the specific context of a Mexican public hospital; therefore, contextual factors such as the healthcare system, training and culture may have influenced the results. This limits the external validity and the generalization for public hospitals. Second, because the implementation occurred in one hospital, a larger number of hospitals and/or further longitudinal research will be needed to deepen understanding of embedding LH to improve efficiency in the supply process. Third, the time periods that were compared, might have different volume of surgical demand, therefore comparing similar periods would better address this issue. Obtained savings and financial information was not allowed to provide due to confidentiality agreement. Finally, we did not directly assess the impact of waste reduction on patient satisfaction and staff satisfaction, which are a very important outcome of LH.

\section{Conclusions}

This study shows that LH implementation following the DMAIC method provides an effective approach to reduce waste; particularly five different wastes were reduced, thereby improving process efficiency. These results have a direct effect on costs reduction, better resources utilization, and reduction of staff processing time, which might lead to better work climate. The fact of using DMAIC with well-defined steps, helped to delimitate the problem and guide for a solution when implementing lean healthcare, therefore lean and six sigma appears to be an effective approach to implement in healthcare processes in order to identify, evaluate, and reduce wastes, increase efficiency and therefore contribute to sustainability. Future research might include the impact of government strategies in healthcare to increase efficiency in developing countries, cultural and socio-technical factors implementing LH and SS within public hospitals, as well as the supply chain management within public healthcare providers have an important gap to be filled.

Author Contributions: all authors have read and agree to the published version of the manuscript. Conceptualization, L.R. and D.T.; methodology, L.R., D.T., Y.B. and J.L.; validation, D.T. and J.L.; formal analysis, L.R. and Y.B.; investigation, L.R. and D.T.; resources, Y.B.; data curation, J.L.; writing-original draft preparation, L.R. and D.T.; writing-review and editing, Y.B., J.L. and A.P.; supervision, Y.B., J.L. and A.P.; project administration, Y.B. and A.P.

Funding: This research received no external funding

Acknowledgments: National Council of Science and Technology of Mexico

Conflicts of Interest: The authors declare no conflict of interest. The funders had no role in the design of the study; in the collection, analyses, or interpretation of data; in the writing of the manuscript, or in the decision to publish the results. 


\section{References}

[1] S. Lingaratnam, D. Murray, A. Carle, S. Kirsa, R. Paterson, and D. Rischin, “Developing a Performance Data Suite to Facilitate Lean Improvement in a Chemotherapy Day Unit," J. Oncol. Pract., vol. 9, no. 4, pp. e115-e121, Jul. 2013.

[2] M. Crema and C. Verbano, "How to combine lean and safety management in health care processes: A case from Spain," Saf. Sci., vol. 79, pp. 63-71, Sep. 2015.

[3] H. Chan et al., "Lean techniques for the improvement of patients' flow in emergency department," World J. Emerg. Med., vol. 5, no. 1, p. 24, Mar. 2014.

[4] N. Westwood, M. James-Moore, and M. Cooke, "Going lean in the NHS Going lean in the NHS," NHS Inst. Innov. Improv., 2007.

[5] M. J. Beck, D. Okerblom, A. Kumar, S. Bandyopadhyay, and L. V. Scalzi, “Lean intervention improves patient discharge times, improves emergency department throughput and reduces congestion," Hosp. Pract. (1995), vol. 44, no. 5, pp. 252-259, Dec. 2016.

[6] R. I. Cohen, “Lean Methodology in Health Care,” Chest, vol. 154, no. 6, pp. 1448-1454, Dec. 2018.

[7] T. G. Zidel, Lean Guide to Transforming Healthcare: How to Implement Lean Principles in Hospitals, Medical Offices, Clinics, and Other Healthcare Organizations, 1 edition. Milwaukee: Quality Press, 2006.

[8] R. Bercaw, Taking improvement from the assembly line to healthcare: the application of lean within the healthcare industry, 1st editio. Boca Raton, Fl.: CRC Press, 2011.

[9] V. Montesarchio, A. Grimaldi, B. Fox, A. Rea, F. Marincola, and P. Ascierto, “Lean oncology: a new model for oncologists," in Journal of Translational Medicine, vol. 10, no. 74, 2012, pp. 1-3.

[10] L. de Souza, “Trends and approaches in lean healthcare," Leadersh. Heal. Serv., vol. 22, no. 2, pp. 121-139, May 2009.

[11] L. B. Costa and M. Godinho Filho, "Lean healthcare: review, classification and analysis of literature," Prod. Plan. Control, vol. 27, no. 10, pp. 823-836, 2016.

[12] Institute of Medicine, The Healthcare Imperative: Lowering Costs and Improving Outcomes, Workshop S. Washington D.C.: The National Academies Press, 2010.

[13] D. L. King, D. I. Ben-Tovim, and J. Bassham, "Redesigning emergency department patient flows: Application of Lean Thinking to health care," Emerg. Med. Australas., vol. 18, no. 4, pp. 391-397, Aug. 2006.

[14] L. Rutman, K. Stone, J. Reid, G. A. T. Woodward, and R. Migita, "Improving patient flow using lean methodology: an emergency medicine experience," Curr. Treat. Options Pediatr., vol. 1, no. 4, pp. 359-371, Oct. 2015.

[15] S. Agarwal et al., "Impact of lean six sigma process improvement methodology on cardiac 
catheterization laboratory efficiency," Cardiovasc. Revascularization Med., vol. 17, no. 2, pp. 95-101, Mar. 2016.

[16] L. R. Duska, J. Mueller, H. Lothamer, E. B. Pelkofski, and W. M. Novicoff, “Lean methodology improves efficiency in outpatient academic Gynecologic Oncology clinics," Gynecol. Oncol., vol. 138, no. 3, pp. 707-711, 2015.

[17] O. Al-Araidah, A. Momani, M. Khasawneh, and M. Momani, “Lead-time reduction utilizing lean tools applied to healthcare: the inpatient pharmacy at a local hospital.," J. Healthc. Qual., vol. 32, no. 1, pp. 59-66, 2010.

[18] M. J. Vermeulen et al., “Evaluation of an emergency department lean process improvement program to reduce length of stay," Ann. Emerg. Med., vol. 64, no. 5, pp. 427-438, Nov. 2014.

[19] B. Umut and P. A. Sarvari, "Applying lean tools in the clinical laboratory to reduce turnaround time for blood test results," Int. J. Adv. Sci. Eng. Technol., vol. 4, no. 1, pp. 1-6, 2016.

[20] S. Kanamori, S. Sow, M. C. Castro, R. Matsuno, A. Tsuru, and M. Jimba, “Implementation of 5S management method for lean healthcare at a health center in Senegal: A qualitative study of staff perception," Glob. Health Action, vol. 8, no. 1, pp. 1-9, 2015.

[21] A. Chiarini and A. Cherrafi, "Improving patient satisfaction using lean manufacturing tools. Case studies from Italy," in 20th Excellence in Services International Conference, 2017, pp. 177-182.

[22] G. Improta et al., "Improving performances of the knee replacement surgery process by applying DMAIC principles," J. Eval. Clin. Pract., vol. 23, no. 6, pp. 1401-1407, Dec. 2017.

[23] J. De la Lama et al., “Using Six Sigma tools to improve internal processes in a hospital center through three pilot projects," Int. J. Healthc. Manag., vol. 6, no. 3, pp. 158-167, Aug. 2013.

[24] M. Ortiz Barrios and H. Felizzola Jiménez, “Use of Six Sigma Methodology to Reduce Appointment Lead-Time in Obstetrics Outpatient Department," J. Med. Syst., vol. 40, no. 10, pp. 1-15, Oct. 2016.

[25] A. D'Andreamatteo, L. Ianni, F. Lega, and M. Sargiacomo, "Lean in healthcare: A comprehensive review," Health Policy (New. York)., vol. 119, no. 9, pp. 1197-1209, Sep. 2015.

[26] R. J. Roberts, A. E. Wilson, and Z. Quezado, “Using Lean Six Sigma Methodology to Improve Quality of the Anesthesia Supply Chain in a Pediatric Hospital," Anesth. Analg., vol. 124, no. 3, pp. 922-924, Mar. 2017.

[27] J. Womack et al., “Going Lean in Health Care,” 2005.

[28] G. Niemeijer, A. Trip, K. Ahaus, R. Does, and K. Wendt, "Quality in trauma care: Improving the discharge procedure of patients by means of Lean Six Sigma," J. Trauma - Inj. Infect. Crit. Care, vol. 69, no. 3, pp. 614-618, Sep. 2010.

[29] Y. Hseng-Long, L. Chin-Sen, S. Chao-Ton, and W. Pa-Chun, "Applying lean six sigma to improve 
healthcare: An empirical study," African J. Bus. Manag., vol. 5, no. 31, pp. 12356-12370, 2011.

[30] B. Gayed, S. Black, J. Daggy, and I. Munshi, “Redesigning a Joint Replacement Program using Lean Six Sigma in a Veterans Affairs Hospital," JAMA Surg., vol. 148, no. 11, pp. 1050-1056, Nov. 2013.

[31] R. R. Cima et al., "Use of Lean and Six Sigma Methodology to Improve Operating Room Efficiency in a High-Volume Tertiary-Care Academic Medical Center," J. Am. Coll. Surg., vol. 213, no. 1, pp. 83-92, Jul. 2011.

[32] S. Trzeciak et al., "Lean Six Sigma to Reduce Intensive Care Unit Length of Stay and Costs in Prolonged Mechanical Ventilation," J. Healthc. Qual., vol. 40, no. 1, pp. 36-43, Nov. 2018.

[33] J. Johnson et al., "Expeditious emergency room referral pathway improves patient access to otolaryngology care," Laryngoscope Investig. Otolaryngol., vol. 2, no. 6, pp. 432-436, Dec. 2017.

[34] H. Martinez-Leon and J. Calvo-Amodio, “Towards lean for sustainability: Understanding the interrelationships between lean and sustainability from a systems thinking perspective," J. Clean. Prod., vol. 142, pp. 4384-4402, Jan. 2017.

[35] United Nations, “The Sustainable Development Agenda,” $2015 . \quad$ [Online]. Available: https://www.un.org/sustainabledevelopment/development-agenda/. [Accessed: 07-Dec-2018].

[36] L. R. Laganga, "Lean service operations: Reflections and new directions for capacity expansion in outpatient clinics," J. Oper. Manag., vol. 29, no. 5, pp. 422-433, 2011.

[37] J. Karstoft and L. Tarp, “Is Lean Management implementable in a department of radiology?," Insights Imaging, vol. 2, no. 3, pp. 267-273, 2011.

[38] P. López-Fresno, “Contribution of Lean Management to Excellence,” Nang Yan Busines J., vol. 1, no. 1, pp. 90-98, Nov. 2012.

[39] S. Pineda Dávila and J. Tinoco González, "Mejora de la eficiencia de un servicio de rehabilitación mediante metodología Lean Healthcare," Rev. Calid. Asist., vol. 30, no. 4, pp. 162-165, Jul. 2015.

[40] W. Ulhassan et al., "Antecedents and characteristics of lean thinking implementation in a swedish hospital: A case study," Qual. Manag. Health Care, vol. 22, no. 1, pp. 48-61, Jan. 2013.

[41] J. I. Ker, Y. Wang, M. N. Hajli, J. Song, and C. W. Ker, “Deploying lean in healthcare: Evaluating information technology effectiveness in U.S. hospital pharmacies," Int. J. Inf. Manage., vol. 34, no. 4, pp. 556-560, 2014.

[42] S. M. Coelho, C. F. Pinto, R. D. Calado, and M. B. Silva, "Process improvement in a cancer outpatient chemotherapy unit using lean healthcare," IFAC Proc. Vol., vol. 6, no. PART 1, pp. 241-246, 2013.

[43] F. Moreira, A. Alves, and R. Sousa, "Towards Eco-Effcient Lean Production Systems," in Balanced Automation Systems for Future Manufacturing Networks, vol. 322, 2010, pp. 100-108. 
[44] D. Baguma, "Public health safety and environment in inadequate hospital and healthcare settings: a review," Public Health, vol. 144, pp. 23-31, Mar. 2017.

[45] L. Gholizadeh, I. Masoudi, K. Hajinabi, and P. Raeissi, “The impact of lean management components on improved quality of public hospitals in Kohgiluyeh and Boyerahmad and Bushehr provinces," Int. J. Med. Res. Heal. Sci., vol. 5, no. 7, pp. 467-472, Jan. 2016.

[46] K. Marley, D. Collier, and S. Goldstein, "The role of clinical and process quality in achieving patient satisfaction in hospitals," Decis. Sci., vol. 35, no. 3, pp. 349-368, Jun. 2004.

[47] C. Hallam and C. Contreras, “Lean healthcare: scale, scope and sustainability," Int. J. Health Care Qual. Assur., vol. 31, no. 7, pp. 684-696, Aug. 2018.

[48] Z. Radnor and S. P. Osborne, “Lean: A failed theory for public services?,” Public Manag. Rev., vol. 15, no. 2, pp. 265-287, Feb. 2013.

[49] L. Costa, M. Filho, A. Rentes, T. Bertani, and R. Mardegan, “Lean healthcare in developing countries: evidence from Brazilian hospitals," Int. J. Health Plann. Manage., vol. 32, no. 1, pp. e99-e120, Jan. 2015.

[50] J. Rodrigues and F. Berssaneti, "Application of lean healthcare in hospital services: a review of the literature (2007 to 2017)," Production, vol. 28, no. e20180009, Jul. 2018.

[51] M. Radwan, “Lean six sigma methodology in Saudi healthcare organizations: Drawing the topography of an unexplored territory," in Global Public Health Congress, 2018, vol. 08.

[52] R. K. Yin, “Yin, R. K. (2009). Case study research: Design and methods (4th Ed.). Thousand Oaks, CA: Sage.," Can. J. Action Res., vol. 14, no. 1, pp. 69-71, 2009.

[53] O. Kasapoglu, "Selection of the Forecasting Model in Health Care," J. Hosp. Med. Manag., vol. 2, no. 2, pp. 1-5, 2016.

[54] A. Vanichchinchai, "The effect of lean manufacturing on a supply chain relationship and performance," Sustain., vol. 11, no. 20, pp. 26-28, 2019.

[55] P. McCulloch, S. Kreckler, S. New, Y. Sheena, A. Handa, and K. Catchpole, “Effect of a 'Lean' intervention to improve safety processes and outcomes on a surgical emergency unit," BMJ, vol. 341, no. 7781, pp. 1043-1046, Nov. 2010.

[56] F. E. Simons, K. H. Aij, G. Widdershoven, and M. Visse, "Patient safety in the operating theatre: How A3 thinking can help reduce door movement," Int. J. Qual. Heal. Care, vol. 26, no. 4, pp. 366-371, 2014.

[57] F. R. Farrokhi, M. Gunther, B. Williams, and C. C. Blackmore, "Application of Lean Methodology for Improved Quality and Efficiency in Operating Room Instrument Availability," J. Healthc. Qual., vol. 37, no. 5, pp. 277-286, Sep. 2015.

[58] M. Castaldi, D. Sugano, K. Kreps, A. Cassidy, and J. Kaban, “Lean philosophy and the public hospital,” Perioper. Care Oper. Room Manag., vol. 3, pp. 25-28, Jun. 2016. 
[59] K. Złotowska and A. Wise, "Polish Dialysis Center Employees Use Visual Management to Increase Safety , Improve Organization of Medical Facility," 2015.

[60] A. J. Fong, M. Smith, and A. Langerman, “Efficiency improvement in the operating room," J. Surg. Res., vol. 204, no. 2, pp. 371-383, Aug. 2016.

[61] C. Tasdemir and R. Gazo, "A systematic literature review for better understanding of lean driven sustainability," Sustainability, vol. 10, no. 7, pp. 1-54, Jul. 2018.

[62] A. Cherrafi, S. Elfezazi, A. Chiarini, A. Mokhlis, and K. Benhida, "The integration of lean manufacturing, Six Sigma and sustainability: A literature review and future research directions for developing a specific model," J. Clean. Prod., vol. 139, pp. 828-846, 2016.

[63] S. Duarte and V. Cruz-Machado, “Modelling lean and green: a review from business models," Int. J. Lean Six Sigma, vol. 4, no. 3, pp. 228-250, Aug. 2013.

[64] G. Muir, How To Get Better Value Healthcare, 2nd editio. Offox Press Ltd., 2011.

[65] F. Mortimer, J. Isherwood, A. Wilkinson, and E. Vaux, "Sustainability in quality improvement: redefining value," Futur. Healthc. J., vol. 5, no. 2, pp. 88-93, 2018.

[66] E. W. Dickson, S. Singh, D. S. Cheung, C. C. Wyatt, and A. S. Nugent, "Application of Lean Manufacturing Techniques in the Emergency Department," J. Emerg. Med., vol. 37, no. 2, pp. 177-182, 2009.

[67] M. D. Iannettoni, W. R. Lynch, K. R. Parekh, and K. A. McLaughlin, "Kaizen method for esophagectomy patients: Improved quality control, outcomes, and decreased costs," Ann. Thorac. Surg., vol. 91, no. 4, pp. 1011-1017, 2011.

[68] P. Mazzocato et al., "How does lean work in emergency care? A case study of a lean-inspired intervention at the Astrid Lindgren Children's hospital, Stockholm, Sweden," BMC Health Serv. Res., vol. 12, no. 28, p. 13, 2012.

[69] E. V. Gijo, J. Antony, J. Hernandez, and J. Scaria, "Reducing patient waiting time in a pathology department using the Six Sigma methodology," Leadersh. Heal. Serv., vol. 26, no. 4, pp. 253-267, Sep. 2013.

[70] K. B. Stone, “Four decades of lean: a systematic literature review," Int. J. Lean Six Sigma, vol. 3, no. 2, pp. 112-132, 2012.

[71] United States Environmental Protection Agency, “The Environmental Professional 's Guide to Lean \& Six Sigma," 2009.

[72] M. Jiménez, L. Romero, J. Fernández, M. del M. Espinosa, and M. Domínguez, “Extension of the Lean $5 \mathrm{~S}$ methodology to $6 \mathrm{~S}$ with an additional layer to ensure occupational safety and health levels," Sustain., vol. 11, no. 14, pp. 1-18, 2019. 
[73] S. Rothenberg, F. Pil, and J. Maxwell, "Lean, green, and the quest for superior environmental performance," Prod. Oper. Manag., vol. 10, no. 3, pp. 228-243, 2001.

[74] J. Souza and J. Alves, “Lean-integrated management system: A model for sustainability improvement,” J. Clean. Prod., vol. 172, no. Icpr, pp. 2667-2682, Jul. 2018.

[75] United Nations, “About the Sustainable Development Goals," 2018. [Online]. Available: https://www.un.org/sustainabledevelopment/sustainable-development-goals/.

[Accessed: 07-Dec-2018].

[76] M. Mazzotta, “Sustainable Development Management Plan for NHS England 2018-2020,” 2018.

[77] United States Environmental Protection Agency, “The Lean and Environment Toolkit,” United States Environmental Protection Agency, Washington D.C., 2007. 